\title{
Mulher comparsa: o testemunho midiático sobre o delito feminino ${ }^{1}$
}

\author{
Comparison woman: media testimony about female crime
}

Lúcia Lamounier Sena ${ }^{2}$

Letícia Silva Azevedo ${ }^{3}$

\begin{abstract}
(...) que esses relatos não constituíssem simplesmente historietas estranhas ou patéticas, mas que de uma maneira ou de outra (porque eram queixas, denúncias, ordens ou relações) tivessem feito parte realmente da história minúscula dessas existências, de sua desgraça, de sua raiva ou de sua incerta loucura" (Foucault, 2006)
\end{abstract}

\section{Resumo}

Este artigo apresenta uma reflexão sobre o testemunho midiático e as dimensões de poder que envolvem os relatos e a memória social. Essa discussão toma como objeto a cobertura jornalística mineira empreendida nos cadernos Cidades dos jornais OTEMPO e o Super Notícia, no período ente 2006/2016, sobre mulheres que atuam no tráfico de drogas. O material de análise que embasou a pesquisa foi tratado de forma qualitativa com auxílio do software NVivo e para alguns cruzamentos estatísticos pelo software SPSS. A discussão sustenta-se no entendimento das tecnologias sociais midiáticas como tecnologias de gênero, um testemunho social legitimado nas narrativas sobre as transgressões femininas, na medida em que se traduz como dispositivos produzidos e produtores das normas de inteligibilidade sobre o outro. Os resultados da pesquisa apontam que a figura da "mulher comparsa", agente destituído da sua potência por uma narrativa que secundariza a sua ação em prol de alguém, mescla com outras posições femininas na atividade do tráfico de drogas, posições categorizadas como Mulher Mãe, Dona de Casa, Mulher Mula. Apesar do Corpos de pesquisa apresentar certa variação das posições das mulheres em atividade criminosa, elas são discursivamente posicionadas em relação à agência masculina. $\mathrm{O}$ artigo aponta o testemunho midiático como uma tecnologia social de gênero que opera através do recorrente enquadramento da atividade das mulheres como comparsas. A secundarização da atividade das mulheres no material analisado indica a consolidação de um discurso produtor das diferenças como sentidos hierárquicos despontencializadores da agência feminina no crime do tráfico.

Palavras-Chave: Testemunho midiático; Mulheres; Tráfico de Drogas.

\footnotetext{
1 Trabalho primeiramente apresentado no II Seminário Mídia e Memória Testemunhas e Testemunhos do Contemporâneo do Grupo de Pesquisa Mídia e Memória - Coord. Prof. Dr. Mozahir Salomão Bruck.

${ }^{2}$ Doutora em Ciências Sociais, coordenadora da Pesquisa TECNOLOGIA SOCIAL DE GÊNERO:

sistema mídia e mercados de drogas ilegais, FIP/CNPq, 2018. E-mail: 1lsena.bh65@gmail.com

${ }^{3}$ Graduanda em História, Bolsista FIP - PUC MINAS. Email: leticiadogs2011@ hotmail.com
} 


\begin{abstract}
This article presents a reflection on media testimony and the dimensions of power that involve reports and social memory. This discussion takes as its object the journalistic coverage in Minas Gerais undertaken in the city notebooks of the newspapers OTEMPO and Super Notícias, between 2006/2016, about women working in drug trafficking. The analysis material on which the research was based was treated qualitatively with the aid of the NVivo software and for some statistical crosses by the SPSS software. The discussion is based on the understanding of social media technologies as gender technologies, a legitimate social testimony in the narratives about female transgressions, insofar as it translates as devices produced and producers of intelligibility norms about the other. The results of the research show that the figure of the "female companion", an agent deprived of her power by a narrative that makes her action in favor of someone secondary, mixes with other female positions in the activity of drug trafficking, positions categorized as Woman Mother, Housewife, Mule Woman. Although the Research Bodies present a certain variation in the positions of women in criminal activity, they are discursively positioned in relation to the male agency. The article points to the media testimony as a social technology of gender that operates through the recurrent framing of the activity of women as cohorts. The secondary nature of women's activity in the analyzed material indicates the consolidation of a discourse that produces differences as hierarchical meanings of the female agency in the crime of trafficking.
\end{abstract}

Keywords: Media Testimony; Women; Drug trafficking.

\title{
Introdução
}

Um testemunho é portador de uma narrativa que convoca uma evidência factual e temporal específica. Essa narrativa pode ser considerada potente pela força do seu relato de dar visibilidade pública a certos agentes, às suas ações e às temáticas sociais implicadas.

Na posição daquele que traz um relato sobre o vivido ou que faz referência ao vivido por outrem, um testemunho é uma narrativa envolta em um quadro de interpelação moral, de reafirmação ou contestação do regime de verdade pelo qual se estabelece o reconhecimento ou ausência de reconhecimento de si e/ou do outro (BUTLER;2015). Entendido como um testemunho sobre o outro, o sistema mídia, por meio da notícia, é um dispositivo testemunhal que se apresenta em uma relação desigual de poder que, com frequência, é estabelecida no embate entre o silêncio inicial daquele/daquilo que é relatado e a palavra amplificada daquele que relata.

Na perspectiva do crime do tráfico de drogas e gênero, objeto de nossa pesquisa, o silenciamento do relatado é operado duplamente. Por um lado, o fato de o sistema mídia se apresentar como um sistema perito, nos termos de Giddens (1990), instituição social de um sistema que pressupõe que o guardião da verdade não seja o sujeito que a profere, e sim a instituição que ele representa. O mediador em questão não é somente o suporte do discurso sobre a verdade, mas também é o portador da interpretação, aquilo que torna a informação 
creditada. É nesse aspecto que a confiança se estabelece, ou seja, não somente pelo discurso em si, mas pela confiança em relação à autoridade do mediador e o discurso que pratica legitimador da realidade do mundo a que procura dar visibilidade (SENA, 2016, pag. 5). Imbuído da perícia jornalística, o testemunho na forma de uma narrativa noticiosa interpela o outro em sua existência moral transgressora: uma mãe, filha, uma esposa, enfim, um papel de gênero transgredido pela prática do tráfico. Uma testemunha que ao mesmo tempo em que apresenta a sua narrativa disponibiliza os termos morais e institucionais para o reconhecimento da legitimidade do seu relato.

A dimensão moral e institucional do testemunho midiático sobre o gênero e suas práticas “desviantes" aparece no estudo de Elizabeth Jelim (2002) sobre o gênero na memória do período da ditadura na Argentina (1976-1986). Por um lado, as representações do masculino se naturalizaram na perspectiva dos militares e dos guerrilheiros. $\mathrm{O}$ rosto masculino da guerra interna. No seu oposto desviante, as representações midiáticas da masculinidade ou da dessexualização das guerrilheiras em contraponto à feminilidade das organizações de direitos humanos, chefiadas por mulheres e seus incontroversos ícones, lenços brancos, flores, fotografias e painéis cujas fotos dos desparecidos testemunhavam a sua existência de mães, esposas ou namoradas.

Judith Butler (2015) propõe uma reflexão sobre as implicações do relato sobre si, situação em que somos convocados a apresentar uma narrativa sobre nós mesmos. Essa interpelação é um encontro com o outro (que nos convoca ao relato) e ao mesmo tempo nos (re)constrói em termos dos limites dos quadros histórico, sociais e morais que postulam uma inteligibilidade sobre os agentes. O "eu" e o outro sobre o qual agimos no processo do relato.

Transpondo a proposição acima apresentada para os interesses deste artigo, buscamos apresentar o testemunho midiático como uma interpelação do outro (a quem não é dada a oportunidade de fazer um relato sobre si) no seu agir sobre o mundo, um relato sobre uma mulher flagrada no seu encontro com a lei devido ao crime do tráfico de drogas. Relato social que se inicia através do testemunho midiático, ou seja, uma notícia gerada a partir das fontes oficiais, um boletim de ocorrência policial, fonte através da qual o jornalista apresenta um testemunho público de um delito prescrito na Lei ${ }^{\circ} 11343 / 2006$, cometido por uma mulher. A testemunha interpela, mas não dá voz ao interpelado.

A discussão sobre o acontecimento midiático como um testemunho proposta pelo artigo faz parte de uma pesquisa financiada pelo FIP PUC Minas/CNPq sobre tráfico de drogas, mídia 
e gênero e se insere na linha de pesquisa "Simbologias do Mal na Midiatização do Crime e da Violência" junto ao grupo de pesquisa do CNPq, Mídia e Memória.

O corpus de pesquisa foi constituído por notícias publicadas predominantemente nos veículos online dos jornais O Tempo e Super Notícias. O recorte temporal definido foi de uma década, abrangendo os anos de 2006 (ano de promulgação da nova lei antidrogas 11343/2006) até 2016. O material de análise que embasou a pesquisa foi tratado de forma qualitativa com auxílio do software NVivo e para alguns cruzamentos estatísticos pelo software SPSS.

$\mathrm{O}$ artigo foi dividido em duas partes. Na primeira parte, discute-se o entendimento das tecnologias sociais midiáticas como tecnologias de gênero, dispositivos produzidos e produtores das normas de inteligibilidade sobre o outro e, portanto, como um testemunho social legitimado nas narrativas sobre as transgressões femininas. Na segunda parte, apresentamos os resultados da pesquisa, em que a figura da "mulher comparsa", agente destituído da sua potência por uma narrativa que secundariza a sua ação em prol de outro alguém. Essa posição se mescla em todas as demais categorias identificadas no corpus de pesquisa, demonstrando que apesar da variação das posições das mulheres relatadas em uma ação criminosa, elas são fundamentalmente vinculadas e circunscritas à agência masculina.

Nas considerações finais explicitamos que os fatos noticiados são atuais, mas compreendidos como maneiras de significar social e historicamente situadas, sendo assim, trata-se de enquadramentos que não nascem da autonomia jornalística dos jornais analisados. Nesse sentido, esse estudo se debruça sobre práticas de memória, tecnologias sociais de memória e gênero.

\section{Tecnologias Sociais de Gênero e Testemunhos}

Uma técnica social atua sobre uma dimensão de realidade e a sua potência é relativa aos acionamentos sociais que lhes são decorrentes e, portanto, a sua capacidade de alterar as formas de percepção, de discursos e ações sobre o mundo. Um dispositivo não se apresenta como uma materialidade em si. Inscreve-se em um complexo normativo que abarca de instituições a pressupostos científicos e filosóficos, nos padrões dos patrimônios arquitetônicos, entre outros elementos. Uma técnica social, entendida como um dispositivo, estrutura-se em uma rede cujas conexões entre uma diversidade de contextos que a materializam na dinâmica social como uma estrutura mediadora dos sentidos hegemônicos (AGAMBEM, 2005).

As tecnologias sociais são dispositivos produzidos e produtores das normas de inteligibilidade sobre si e sobre o outro, em uma lógica contextual de "normas que estabelecem os limites do que é considerado uma formação inteligível do sujeito dentro de determinado 
esquema histórico das coisas" (BUTLER, 2015, p.29). Nesse sentido, nosso pressuposto é de que o sistema mídia, aqui recortado pelas práticas jornalísticas, pode ser entendido como um dispositivo testemunhal cujo poder se estabelece por uma rede de instituições e interações sócio técnicas, de naturezas diversas, que são capazes de produzir, difundir e sustentar narrativas hegemônicas sobre os fatos sociais.

Entende-se por narrativa midiática um testemunho, uma técnica social de produção discursiva que não está alheia às relações de poder contextuais e históricas que lhe constituem como um testemunho legítimo e que também participam da sua construção, conteúdo e forma. No processo de produção e difusão de um testemunho midiático — um acontecimento — estão envolvidas as negociações entre as práticas profissionais, os interesses dos agentes envolvidos, os enquadramentos, as saliências, destaques e representações formatadores de uma narrativa sobre o mundo social (ZIZECK, 2017; SILVERSTONE,2012).

Na perspectiva de Slavoj Zizek (2017), o acontecimento não traz em si um conteúdo específico cuja totalidade de sentidos já está configurada como algo a ser exposto. À medida em que algo vai se tornando público é que se apresenta como acontecimento, "um efeito que excede suas causas e que se engendra como uma conexão de sentidos" (idem, pag.11). Isso significa entender o acontecimento não como um fato, mas como algo construído pelos parâmetros de uma narrativa que é ao mesmo tempo uma forma e uma técnica social discursiva.

Para referenciar a mídia como uma tecnologia de gênero, na perspectiva de Lauretis (1987), é necessário, primeiramente, situar o discurso como produtor de posições de gênero. Nesse sentido, assumimos a perspectiva de Michel Pecheux (1988), do discurso como um fato estrutural ordenado pela perspectiva do simbólico. O discurso, como um campo de disputa, é atravessado pelas interpretações advindas dos múltiplos processos interpretativos e, portanto, não deve ser compreendido em si, mas sim como maneiras de significar. É importante considerar que a construção de um discurso é permeada pelo contexto de sua produção e pela memória do sujeito que o produz (OLIVEIRA, 2005). Os agentes sociais são constantemente transpassados por práticas discursivas. No processo de produção e interpretação dos testemunhos midiáticos se faz presente uma memória sócio-histórica que opera através dos condicionantes do próprio agente da interpretação, assim como os operadores relativos à apropriação, à negociação ou o rechaço dos sentidos disponibilizados (GREGOLIM, 2007; POLLACK, 1982;1989).

O tráfico de drogas como uma prática discursiva midiática sobre o fenômeno da criminalidade e gênero aciona a operacionalização da perspectiva científica como um 
dispositivo acionador dos condicionantes sociais interpretativos. Em um estudo anterior (SENA, 2018), argumentei que entendimento da criminalidade feminina, como um desvio psíquico, biológico e social de gênero ao longo do Século XX foi edificado por bases estatísticas de crimes predominantemente masculinos. A narrativa científica daí decorrente era de que o gênero (tido como o correlato biológico do sexo) implica em condicionantes do perfil e das próprias práticas criminosas. No caso do Brasil, esses pressupostos sustentaram a formação das prisões femininas nas décadas de 1930/1940.

Na perspectiva de Butler $(1987$; 2006), a repetição das ênfases, recortes e práticas discursivas específicas materializam os atos e os agentes envolvidos com as práticas criminais como diferenças de natureza sexual e moral. O mesmo padrão ideológico se aplica para a mídia geral, tornando-a como uma tecnologia social de gênero cujos padrões discursivos referendam dados essencializadores das características criminais que passam a ser consideradas intrínsecas aos agentes femininos.

O estudo pioneiro de Dulcília Buitoni (1981) sobre a imprensa feminina no Brasil demonstra que as narrativas midiáticas contribuem para maximizar a diferença entre qualidades reais e ideais que categorizam as mulheres, colaborando na formação de um mito sobre a mulher, na construção de uma mulher - mito: uma identidade feminina genérica e atemporal, que não valoriza a mulher individual e histórica e seu contexto social.

No que tange à tecnologia social de gênero, o dispositivo midiático reforça a perspectiva metodológica da genealogia de Foucault (2000), no sentido de que historicamente a essencialidade constitutiva do gênero permanece, para além do campo midiático, como uma referência para análise do fenômeno gênero e criminalidade. No caso das mulheres, essencialmente loucas, apaixonadas, falsas ou vítimas são os argumentos simbólicos, políticos e institucionais que permanecem alimentando o debate, as representações e a própria constituição social do sujeito "gendrado". (SENA; MORAIS, 2017).

No próximo tópico apresentamos o testemunho midiático da "Mulher Comparsa", vinculação de uma prática criminal feminina à uma figura secundária, que talvez não por acaso seja um homem, na figura de um marido, filho ou chefe de uma quadrilha.

Através desse recorte da pesquisa global identificamos o testemunho midiático como um dispositivo discursivo que referenda a formação dos agentes "em relação a um conjunto de códigos, prescrições ou normas(...) que estabelecem os limites do que será considerado uma formação inteligível do sujeito" (BUTLER, 2015, PAG. 29). 
A recorrência dessa categoria no material analisado demonstra que a posição de Mulher Comparsa se mescla a outras categorias analisadas, tais como as Mães, as Mulas, ou seja, pessoas que fazem o transporte da Droga, as traficantes comerciárias e as Donas de Casa.

\section{Comparsas: testemunhos midiáticos e essências de gênero}

No conjunto do material analisado, a categoria denominada mulher comparsa é aquela que aparece com maior recorrência, representada pelo montante de 63,6\% das notícias. A categoria comparsa diz respeito à mulher cuja atuação é discursivamente posicionada como coadjuvante no processo de comercialização, estando ligada a um traficante, quadrilha ou uma gangue. Esta ligação pode ser apenas profissional, mas também se enquadram, nesta categoria, mulheres que mantém algum tipo de relacionamento afetivo sexual com um traficante ou são familiares deles (mães ou esposas).

Esta posição coadjuvante da mulher aciona modelos binários essencializadores de gênero, modelos estes que vinculam o sexo biológico ao comportamento, acarretando a naturalização do campo de ação feminina como o campo do privado e a ação masculina ao campo do público. Flávia Biroli (2018) aponta que a dualidade entre as esferas públicas e privadas permeiam os padrões de sociabilidade e constroem a percepção da vida doméstica como natural, espaço essencialmente "destinado" à mulher.

As notícias, ao associarem a prática criminosa feminina ao agente masculino, constroem um discurso que acaba por justificar a transgressão da mulher pela associação ao homem, representando - a como coadjuvante de sua própria ação. A nuvem de palavras, apresentada na Figura 1, ilustra essa categoria. 
Figura 1 - Nuvem de Palavras

\section{Mulher Comparsa}

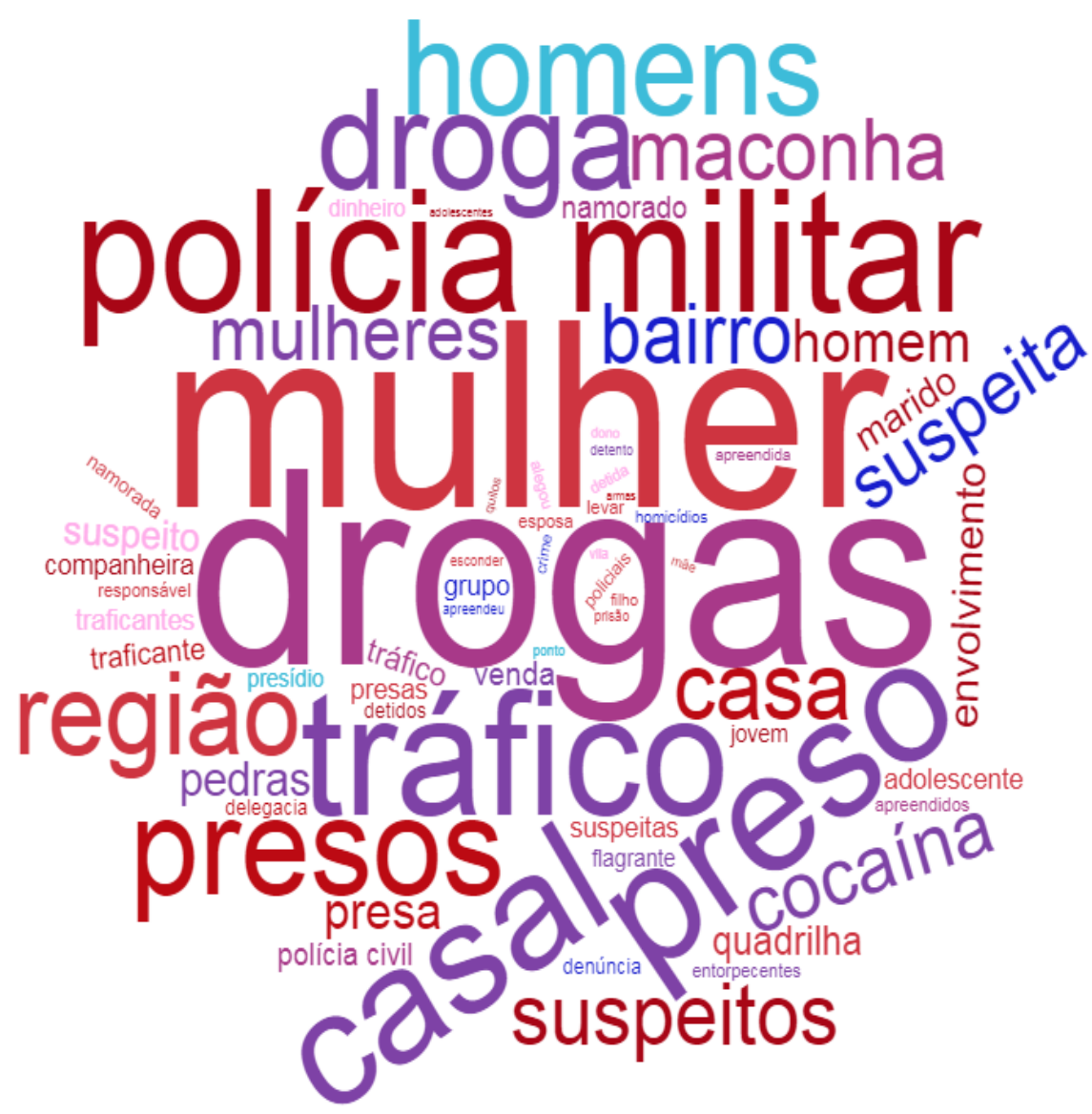

Fonte: Produzido pelas autoras

O vínculo da transgressão feminina com a ação masculina e o espaço privado ou regional de ação dessas mulheres pode ser lido na centralidade da palavra "drogas" que correlaciona o termo "mulher" com a ideia de uma ação conjunta, por exemplo, na proximidade das palavras "mulheres", "bairro", "homem", "marido", suspeita" e no topo da nuvem "polícia militar" e "homens" . Na parte inferior da nuvem a palavra "drogas" está próxima aos termos "tráfico", “casal”, "preso", "casa" e aos plurais, "presos" e "suspeitos", demarcando novamente uma ação transgressora de comparsa

A situação de comparsa, ação que é realizada em conjunto, está presente nas matérias que tem como foco a participação da mulher nas quadrilhas e marcação do gênero no plural. A recorrência da palavra "polícia" tanto indica a fonte de onde foram extraídas as matérias quanto tem o efeito simbólico de marcar a repressão a essa transgressão feminina: (...) Segundo os policiais, ela e o irmão, que não foi encontrado, seriam traficantes na região. A mulher teria a função de armazenar a droga e o homem é quem vendia o entorpecente. (SOARES, 2012 
A posição discursiva de mulher comparsa é construída reafirmando uma posição subordinada ou aliada a outrem, em geral um homem. Nas notícias, a participação feminina é evidenciada na formação das quadrilhas pelo fato da ação criminosa não ser representada como um ato passível de ser protagonizado de forma isolada [por elas]. A relação das mulheres com uma quadrilha ou com um traficante é de forma recorrente descrita através da qualificação da ação de responsável por esconder a droga, vigiar o local onde a droga é armazenada.

Enquadram-se, também, nessa categoria as notícias nas quais a participação feminina no tráfico é justificada pela coação de um homem, de uma quadrilha ou de uma gangue. Normalmente essa coação, nas matérias, é associada a motivos financeiros: necessidade de ganhar dinheiro ou pagamento de alguma dívida. A justificativa da necessidade financeira de entrar no tráfico é frequente nas notícias nas quais as mulheres são protagonistas. Assim, esta mulher não participaria do tráfico por sua vontade própria, mas por obrigação ou necessidade. Essa necessidade pode ser real, mas é importante evidenciar que ela é usada como justificativa recorrente no discurso sobre a mulher no tráfico. Desta forma, a agência da mulher traficante é justificada pela coação e não por suas motivações pessoais, retirando a autonomia da ação criminosa feminina

Em sua defesa, a suspeita E. A. S. afirmou que foi ameaçada na noite anterior pelo suposto traficante. "Ele disse que era para eu guardar a droga até amanhã. Ele fez uma ameaça para mim e disse que se eu não guardasse que ele me acertava. Ele também falou que quando fosse pegar a droga que ia me dar um dinheiro para não comentar nada" justificou a mulher. (SUSPEITO,2012)

Quando a ação feminina não perde o protagonismo pela relação com o parceiro (ambos são indicados como traficantes), o envolvimento é de natureza familiar. As funções no crime do tráfico são descritas através de uma hierarquização de posições, ou seja, como se as mulheres atuassem somente como subordinadas às pessoas responsáveis pela venda da droga, geralmente homens.

Os padrões normativos de masculinidades e feminilidades socialmente aceitos vinculam a posição da mulher no campo do lar, da casa, da família, enquanto ao homem compete a ação pública:

Cumprindo mandado de busca e apreensão, os policiais foram até a casa de um homem conhecido como Bruninho, de 20 anos, que, segundo a PM, comanda o tráfico na região. A mãe e a irmã dele, que estavam na casa, foram presas. Bruninho teria sido preso pouco tempo depois em um hospital da cidade, onde acompanhava a namorada. Uma tia, um tio e um primo do rapaz, de 17 anos, também foram presos suspeitos de envolvimento com o tráfico. (NOGUEIRA; LOMBARDI, 2009)

A Polícia Militar prendeu na noite dessa quarta-feira (2) um homem e uma mulher suspeitos de envolvimento com o tráfico de drogas no bairro Nova Cintra, na região 
Oeste de Belo Horizonte. (...) A polícia suspeita que a droga pertença ao homem. Já a mulher, seria a vigia do local. (PENNA, 2009)

A ex-mulher dele, Mara Joana Targino da Silva, 22, e Andreia Cristina Mota dos Santos, 23, segundo a polícia, vigiavam o local em troca de drogas, foram detidos. (RAMOS, 2006)

Quadrilha investigada que produzia pelo menos 100 quilos de drogas, maconha, cocaína e crack, foi presa. O chefe é Falcão, encontrada em uma favela de São Paulo. Sua mulher era responsável pela contabilidade. (MARTINS, 2012)

Nos excertos das matérias acima apresentadas, a função da mulher é ser uma vigia em detrimento de um homem, o agente central, o traficante. Apesar de terem sido detidos juntos, é reiterado que a ação criminosa rentável não pertence à mulher, cuja função seria a de guardar a droga, enquanto o proprietário, "o dono", seria apenas o homem. A suposta "isenção de culpa" ou secundarização da atividade criminosa, é operada através do protagonismo masculino na transgressão e a posição da mulher como coadjuvante no processo

A Polícia Militar apreendeu na madrugada desta quarta-feira (20) uma adolescente de 15 anos suspeita de comandar o tráfico de drogas no aglomerado da Sopa, no bairro São Gabriel, região Nordeste de Belo Horizonte. Segundo a Polícia Militar, a menor assumiu o tráfico de drogas no lugar do namorado que está preso acusado do mesmo crime. (PENNA, 2010)

Militares do Batalhão de Rondas Táticas Metropolitanas (Rotam) apreenderam nesta segunda-feira (17) um adolescente de 17 anos e prenderam uma mulher de 28 anos suspeitos de envolvimento com o tráfico de drogas. O dono do material, de 32 anos, não foi localizado. (SOARES, 2011)

A mesma situação foi observada na categoria Mulher Mula, atividade de transporte das drogas. O encargo das Mulas é uma posição de alto risco na dinâmica do tráfico de drogas, sobretudo devido ao deslocamento desse agente para dentro das penitenciárias ou pontos de encontros previamente estabelecidos, sejam eles de nível local, interestadual, nacional e até mesmo transnacional.

A Mula como um significante de mulher ocupa nas notícias a narrativa de um alguém que está em uma posição de servir, de ser acessória em uma prática de maior valor, de supostamente posicionar-se distante das instâncias mais altas de poder na hierarquia do tráfico.

Nessa categoria destacamos a associação desse agente e sua posição hierárquica de gênero na posição afetiva-sexual ou familiar como o suposto proprietário da droga transportada, por ameaça e/ou necessidade de financiar o vício ou amparar a família

Pressionadas, elas acabaram confessando que foram contratadas como "mulas" (como são chamadas as pessoas que transportam drogas) por um traficante do bairro Copacabana. Elas indicaram a casa do suspeito e os militares foram até lá. (O TEMPO, 2009) 
Duas mulheres foram presas em Ribeirão das Neves, região metropolitana de Belo Horizonte, acusadas de envolvimento com o tráfico de drogas. Com elas, a polícia apreendeu um quilo de crack e uma balança de precisão. De acordo com a Polícia Civil, as mulheres foram presas dentro de um ônibus coletivo. A suspeita é de que elas tenham ligação com um traficante que atua nas cidades de Brumadinho e Sarzedo, também na região metropolitana de Belo Horizonte. (LOMBARDI, 2009)

O referente Mulher Mula tem na descrição do acontecimento noticiado a qualificação de um agente através da apresentação da sua ação de servir ao outro, carregar um fardo fatalmente de um homem. Destaca-se no corpo das matérias analisadas a presença de uma dicotomia relacional de gênero que estabelece a moralidade que é essencial da atividade de Mula. Essa dicotomia é operacionalizada pela hierarquização do agente masculino como o proprietário da droga ou quando noticiadas na figura de protagonistas do ato criminoso esta ação é devido à sua ligação com um homem (marido ou namorado):

\footnotetext{
Segundo o delegado de plantão Tito Barichello, Fagna disse que a droga era para Renan Leal Gomes, de 25, que está cumprindo pena na cadeia por cometer violência doméstica contra outra mulher. "Ela alegou que eles são namorados e que ela quis agradá-lo ao levar os entorpecentes (JARDIM, 2014)

Duas mulheres foram presas em flagrantes quando estavam transportando drogas na rodoviária. Dona de casa confessou que ela e o marido recebiam $\mathrm{R} \$ 200,00$ por mês para venderem drogas de traficante. (CARVALHO, 2008)
}

A hierarquia de funções é perceptível, também, no enfoque ao pagamento destinado para as mulheres no tráfico. A descrição do armazenamento da droga ou vigia do esconderijo é, por vezes, nas matérias, acompanhada da descrição do valor pago para realização desta tarefa. Ao ressaltar o pagamento realizado e seu valor baixo, a notícia evidencia a posição vulnerável e secundária desta mulher no tráfico de drogas, ao mesmo tempo que reafirma a moral socialmente aceita de que "o crime não compensa", menos ainda para mulheres

O mesmo local, a mesma acusada, cometendo o mesmo crime: o tráfico de drogas.
Assim uma adolescente de 16 anos foi apreendida na manhã de ontem. Segundo a
Polícia Militar (PM), a jovem estava em um beco do bairro Jardim Leblon, região de
Venda Nova, na companhia de outros dois homens, de 19 e 27 , que portava um
revólver calibre 38 , informou a polícia. (...) Segundo o policial, M. contou que dava
três pedras de crack para cada dez outras que a menina vendia para ele a um
preço de R\$ 10. "Ele contou que pagou R\$ 1.200 pela droga e estimava conseguir
de volta R\$ $\mathbf{5 . 0 0 0}$ com as vendas. (JOVEM, 2007)

De acordo com o cabo, a dona de casa contou ter recebido $\mathbf{R} \$ \mathbf{1 0 0}$ de um traficante para esconder o crack. Ainda conforme a mulher, ela teria recebido a mercadoria ontem mesmo e repassado parte para o adolescente vender. (RAMOS, 2009)

Outra situação da Mulher Comparsa pode ser observada na categoria Traficante Comerciária, nomenclatura que enquadra mulheres posicionadas como efetivamente comercializadoras de drogas. O destaque para as matérias analisadas é de um discurso que 
operacionaliza essa transgressão feminina através do enquadramento de um perfil local, doméstico e derivado de uma relação familiar ou afetiva-sexual

A irmã do traficante Roni Peixoto, E. P. S., de 53 anos, conhecida como "Rata" ou "Gorda", foi presa pela polícia civil no centro de Belo Horizonte(...). (EMERICH, 2016)

A mulher presa é irmã de um dos grandes traficantes da região que também foi preso no início do mês (COSTA, 2010 )

De maneira semelhante às já descritas, a ação da comerciária, em grande parte das notícias, vinculada a um relacionamento afetivo - amoroso ou devido a um vínculo familiar. Historicamente, a produção discursiva conformadora das essencialidades de gênero posiciona as mulheres no campo sentimental e o homem no campo da racionalidade. Nos estudos sobre criminalidade feminina a ideia de uma essência ligada ao cuidado, à preservação da vida e à não violência como fundamento explicativo daquilo que se nomeia como "uma mulher" e, portanto, dos sentidos da transgressão criminal feminina, permaneceu como uma matriz explicativa, durante grande parte do século XX (STEFFENSMEIER; ADAN,1996).

Os relatos sobre a comercialização de drogas praticada pelas mulheres vinculam essa ação aos relacionamentos afetivos, alimentando um estereótipo socialmente reproduzido do crime feminino "em nome do amor" ou o "amor bandido"

Uma mulher de 25 anos foi presa na tarde desta quarta-feira (26) suspeita de tráfico de drogas no bairro São José, região da Pampulha, em Belo Horizonte. De acordo com a Polícia Militar, ela é esposa de um suposto traficante da região. (DA REDAÇÃO, 2009)

Militares foram até o cômodo e encontraram Mula Manca com a companheira, uma mulher de 34 anos. Com ela foram encontrados dois celulares, uma porção de maconha e R\$10 mil em dinheiro. (CAETANO, 2016)

Nesta quarta, cinco homens e uma mulher - companheira de um dos líderes foram presos e um adolescente foi apreendido. (DA REDAÇÃ̃, 2015)

Mesmo quando as mulheres se enquadram em posições hierarquicamente importantes, como por exemplo as de comando ou distribuição, sua ação é sempre narrada na posição de parceria afetiva-sexual ou matrimonial com um homem. "Ela" é a "mulher" desse homem [que comanda]. Ao ressaltar o vínculo afetivo, o discurso reproduzido acaba por retirar a autonomia na ação feminina, tal qual ilustrada no trecho da matéria a seguir:

Uma quadrilha especializada no tráfico de drogas foi desarticulada em Poços de Caldas, no Sul de Minas, após a prisão de sete pessoas e a apreensão de três adolescentes. (...) De acordo com o delegado Carlos Camargos, as prisões dos envolvidos tiveram início na noite da última quarta-feira e terminaram na madrugada desta sexta-feira com a prisão de uma mulher de 33 anos que seria a líder do grupo.

"Ela é casada com um homem conhecido aqui como Carioca. Ele é que 
comandava o comércio de crack na região, e foi preso por tentativa de homicídio. (SILVEIRA, 2009)

Seguindo uma denúncia anônima, policiais militares apreenderam na tarde desta sexta-feira (22) uma adolescente de 17 anos suspeita de tráfico de drogas. Segundo a PM, ela e o marido são responsáveis por distribuir cocaína no bairro Alto das Flores e no centro de Betim, na região metropolitana da capital. (NUNES, 2010)

Finalmente, destacamos as mulheres que na categorização do material foram enquadradas como Mãe, também mesclam-se com a categoria Comparsa. As "mães" são figuradas nas notícias em ações coadjuvantes com os filhos ou na posição de garantidoras do sustento familiar pela atividade criminosa. Nos variados sentidos e situações em que se encontram esses enquadramentos a respeito da maternidade, a análise demonstra a construção discursiva da moralidade de gênero. Essa operacionalização é dada pela suposta discrepância entre o papel social materno com a agência criminosa.

Nas notícias as mulheres são relatadas em posição de subordinação, coadjuvantes no contexto do tráfico de drogas, mas a moralidade evidenciada está centrada na posição da maternidade como um instrumento estrategicamente acionado para a ocultação da prática do tráfico de drogas. A ação criminosa das "mães comparsas" é enquadrada no ambiente do lar, às vezes sua ação é em defesa desse lar/família e pelo envolvimento com um homem integrante da família, o chefe do tráfico na região, que ocupa a mais alta posição na hierarquia do tráfico

\footnotetext{
No local, a PM apreendeu o adolescente e apreendeu a droga, uma balança de precisão e diversos documentos. A mãe do suspeito, uma mulher de 32 anos, que também estava na residência foi detida junto com seu filho. (O TEMPO, 2009)

Ela foi flagrada dentro de sua residência com 18 pedras de crack, além de R $\$ 180 \mathrm{em}$ dinheiro. Segundo o sargento Jota Araújo Alves, da $3^{\text {a }}$ Companhia da Rotam, a mulher tem cinco filhos menores e, ao ser detida, justificou estar vendendo drogas para saldar uma dívida de $\mathbf{R} \$ 1.200$ com dois traficantes. (O TEMPO, 2007)

Ele foi abordado e preso dentro de casa, no bairro Nova Esperança, quando teria confessado que traficava e que o esquema contava com a participação da própria mãe, de 39 anos. (...) Dentro da residência do suspeito, os policiais encontraram aproximadamente R\$ 559 em dinheiro, nove buchas de maconha, nove pedras de crack, uma balança de precisão, várias jóias, além de extratos bancários e comprovantes de depósito no valor de R \$ 15 mil. Mãe e filho foram encaminhados para a delegacia da cidade, juntamente com todo o material apreendido. (LOMBARDI, 2009)
}

\section{Considerações Finais}

Iniciamos este artigo afirmando que a potencialidade de um testemunho se estabelece não somente pela evidência factual e temporal que traz consigo, mas pela amplitude da sua narrativa em tornar pública determinados agentes, ações e contextos. Ao final gostaríamos de colocar em relevo as relações de poder presentes no testemunho. Poder que pode indicar 
silêncios, demarcar a positividade da norma, mesmo quando ela implica em dominação, quando indica o não reconhecimento, salienta a diferença como desigualdade.

Como anteriormente apontado na perspectiva de Butler (2015), não há um relato sobre si (e, portanto, sobre o outro) fora dos contextos e normas sociais e históricas que estabelecem as ordenações que me tornam e tornam o outro reconhecido como sujeito. As normas presentes nos relatos não são prescrições, são produtoras dos agentes e do próprio relato.

Ao alçarmos a mídia à categoria de testemunho, realçamos a força do seu poder discursivo que não simplesmente traz representações, mas sim atravessa a constituição dos agentes. No entanto, esse testemunho nem sempre é dado frente a uma audiência cujos poderes são equivalentes à amplitude do relato midiático. Nesse sentido, o testemunho pode ser também produtor de silenciamentos.

O testemunho midiático deve ser observado na sua constituição social como um dispositivo. Entrelaçado e entrelaçador de elementos cuja rede de conexões lhe confere a categoria de sistema perito: o portador de uma verdade por ele criada e ao mesmo tempo interpretada. Constituidor de sentidos disponibilizados às audiências como a realidade do mundo social. Realidade sobre os fatos, os agentes e suas causalidades constituídas em uma perícia técnica que esse mesmo dispositivo oculta em termos dos interesses que lhe configuram. Autoridade do mediador e do discurso que pratica - legitimador da realidade do mundo a que procura dar visibilidade.

Finalmente, como tecnologia de gênero, o nosso estudo aponta o testemunho midiático como uma narrativa genealógica, entrelaçada ao discurso produtor das diferenças de gênero como sentidos hierárquicos, desigualdade. Essas "mulheres infames", as comparsas no crime, agentes destituídos da sua própria agência. No testemunho que sempre referenda as ações no reforço das essencialidades relativas à maternidade, a forte relação com o espaço doméstico, a paixão, a cumplicidade feminina ou a vitimização. São processos discursivos cujos argumentos simbólicos, políticos e institucionais são constitutivos do sujeito "gendrado". O operador midiático não precede esses argumentos, mas tem se apresentado como eficiente tecnologia política de reafirmação das supostas essencialidades femininas. Não se trata aqui de defender a participação das mulheres no crime do tráfico de drogas, mas de decifrar a natureza do testemunho midiático como um silenciador do outro. Quiçá uma tecnologia social da destituição de gênero. 


\section{Referências}

AGAMBEM, Giorgio. O que é um dispositivo? Outra Travessia. No. 5, $2^{\circ}$ semestre de 2005. p. 9-16. Disponível em:

https://pt.scribd.com/document/89685701/dispositivo-agamben. Acesso em: $12 \mathrm{de}$ fev. de 2018.

BELKNAP, Joanne; HOLSINGER, Kristi. The gendered nature of risk factor for delinquency. Feminist Criminology, v. 1, n. 1, 2006, p. 48-71. Disponível em: http://online.sagepub.com. Acesso em: 28 dez. 2014.

BUTLER, J. Relatar a si mesmo. Crítica da violência Ética. Belo Horizonte, Autêntica, 2015.

BUTLER, J. Variações sobre sexo e gênero - Beauvoir, Wittig, Foucault. In:

CORNEEL, Drucilla; BENHABIB, Syla (Coord.). Feminismo como Crítica da

Modernidade. Rio de Janeiro: Rosa dos tempos, 1987. p. 139-153

Problemas de gênero: feminismo e subversão da identidade. 4. ed. Rio de Janeiro: Civilização Brasileira, 2012.

BUILTONI, Dulcília Helena Schroeder. Mulher de papel: a representação da mulher na imprensa feminina brasileira. São Paulo: Edições Loyola, 1981

GAGNEBIN, Jeanne Marie. História e Narração em Walter Benjamim. São Paulo: Perspectiva, 1999.

GIDDENS, Anthony. As Conseqüências da Modernidade. São Paulo: UNESP, 1991. Cap.1.

GREGOLIN, Maria. Análise do discurso e mídia: a (re) produção de identidades.

Comunicação mídia e consumo, v. 4, n. 11, p. 11-25, 2008 
JELIM, Elizabeth. Los trabajos de la Memória. Espanha, SIGLO XXI de españa Editores, S.A, 2002.

LAURETIS, T. A tecnologia do gênero. Indiana University Press, 1987.Disponível em: http://pt.scribd.com/doc/81873993/A-Tecnologia-do-Genero-Teresa-de-Lauretis. Acesso em: Set. 2013.

FOUCAULT, M.. A Arqueologia do Saber. Rio de Janeiro: Forense Universitária, 2000.

OLIVEIRA, Maria de Fátima Cabral Barroso de. A mídia e as mulheres: feminismos, representação e discurso. São Paulo, 2005

PECHEUX, Michel. O Discurso: estrutura ou acontecimento. Pontes, 1988.

POLLAK, Michael. Memória e identidade social. In: Estudos Históricos, 5 (10). Rio de Janeiro, 1992.

Memória, esquecimento, silêncio. Estudos Históricos, 2 (3). Rio de Janeiro, 1989. Estudos Históricos. Rio de Janeiro, Vol. 2. n. 3, 1989, p. 3-15. Disponível em: http://bibliotecadigital.fgv.br/ojs/index.php/reh/article/view/2278/1417.Acesso 24 de janeiro de 2018.

SENA, Lúcia Lamounier. I Love my White: mulheres no registro do tráfico ilegal de drogas. Belo Horizonte, Editora Puc Minas, 2018.

Tecnologias do Gênero: mídia e mercados de drogas ilegais. Belo

Horizonte, Dispositiva, 2016.

SENA, Lúcia Lamounier. MORAIS, José Maria de. Mídia, Crime e Memória: Tecnologias de gênero. Belo Horizonte, 2017.

THOMPSON, John B. (1998). A mídia e a Modernidade: Uma teoria social da mídia. 5 ed. Petrópolis: Vozes, 2002. 259 p. 
SILVERSTONE, Roger. Por que estudar a mídia. São Paulo: Edições Loyola,2002.

STEFFENSMEIER, D.; ALLAN, E. Gender and crime: toward a Gendered Theory of Female Offending. Annual Reviews of Sociology, n. 22, 1996, p. 459-487. Disponível em: www.annualreviews.org. Acesso em: 13 maio 2014.

ZIZEK, S. Acontecimento- Uma viagem filosófica através de um conceito. Rio de Janeiro, Zahar, 2017.

\section{Fontes}

CAETANO, Carolina. Traficante 'Mula Manca' é preso com companheira em Igarapé. O TEMPO, Belo Horizonte, 22 abr. 2016. Cidades. Disponível em:

<https://www.otempo.com.br/cidades/traficante-mula-manca-e-preso-com-companheira-emigarape-1.1284469> Acesso em: jul. 2020

CARVALHO, Aline. Mulheres flagradas com $50 \mathrm{Kg}$ de maconha. O TEMPO, Belo Horizonte, 13 out. 2010. Cidades. Disponível em: < https://www.otempo.com.br/cidades/mulheres-flagradas-com-50-kg-de-maconha-1.280319> Acesso em: jul. 2020

COSTA, Fernando. Casal é preso com sete quilos de maconha na Vila São José. O TEMPO, Belo Horizonte, 11 fev. 2010. Cidades. Disponível em:

<https://www.otempo.com.br/cidades/casal-e-preso-com-sete-quilos-de-maconha-na-vila-saojose-1.462989> Acesso em: jul. 2020

COSTA, Fernando. Mãe e filhos são detidos por tráfico em Pouso Alegre. O TEMPO, Belo Horizonte, 04 dez. 2009. Cidades. Disponível em: <

https://www.otempo.com.br/cidades/mae-e-filhos-sao-detidos-por-trafico-em-pouso-alegre1.500041> Acesso em: jul. 2020

DA REDAÇÃO. Integrantes de quadrilha de tráfico são detidos em Ribeirão das Neves. O TEMPO, Belo Horizonte, 23 set. 2015. Cidades. Disponível em: 
<https://www.otempo.com.br/cidades/integrantes-de-quadrilha-de-trafico-sao-detidos-em-

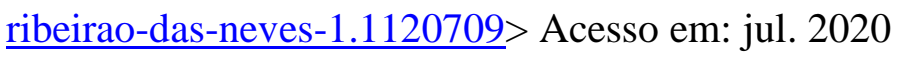

DA REDAÇÃO. Mulher é presa com farta quantidade de drogas na região da Pampulha. O TEMPO, Belo Horizonte, 26 ago. 2009. Cidades. Disponível em:

<https://www.otempo.com.br/cidades/mulher-e-presa-com-farta-quantidade-de-drogas-naregiao-da-pampulha-1.536001> Acesso em: jul. 2020

EMERICH, Daniel. Irmã de traficante Roni Peixoto, 'Rata' é presa em BH. O TEMPO, Belo Horizonte, 21 mar. 2016. Cidades. Disponível em: <

https://www.otempo.com.br/cidades/irma-de-traficante-roni-peixoto-rata-e-presa-em-bh1.1263714> Acesso em: jul. 2020

JARDIM, Flávia. Tenta entrar com drogas escondidas na sua parte íntima. O TEMPO, Belo Horizonte, 23 mar. 2014. Cidades. Disponível em: <https://www.otempo.com.br/o-tempobetim/tenta-entrar-com-drogas-escondidas-na-sua-parte-intima-1.812534> Acesso em: jul. 2020

JOVEM é apreendida pelo mesmo crime. O TEMPO, Belo Horizonte, 15 nov. 2007. Cidades. Disponível em: <https://www.otempo.com.br/cidades/jovem-e-apreendida-pelomesmo-crime-1.303266> Acesso em: jul. 2020

LOMBARDI, Renato. Duas mulheres são presas em Ribeirão das Neves por Tráfico de Drogas. O TEMPO, Belo Horizonte, 16 jul. 2020. Cidades. Disponível em: < https://www.otempo.com.br/cidades/duas-mulheres-sao-presas-em-ribeirao-das-neves-portrafico-de-drogas-1.543634> Acesso em: jul. 2020.

LOMBARDI, Renato. Mãe e filho são presos por tráfico em Ipatinga. O TEMPO, Belo Horizonte, 04 ago. 2009. Cidades. Disponível em: < https://www.otempo.com.br/cidades/mae-e-filho-sao-presos-por-trafico-em-ipatinga1.540445> Acesso em: jul. 2020. 
MARTINS, Tabata. Casal é preso por esconder droga e dinheiro em fralda descartável no Triângulo Mineiro. O TEMPO, Belo Horizonte, 16 mar. 2011. Cidades. Disponível em: $<$ https://www.otempo.com.br/cidades/casal-e-preso-por-esconder-droga-e-dinheiro-em-fraldadescartavel-no-triangulo-mineiro-1.429091> Acesso em: jul. 2020

MARTINS, Tabata. Quadrilha que processava $100 \mathrm{Kg}$ de drogas por mês é presa em Porto Alegre. O TEMPO, Belo Horizonte, 05 abr. 2012. Cidades. Disponível em: < https://www.otempo.com.br/cidades/quadrilha-que-processava-100-kg-de-drogas-por-mes-epresa-em-pouso-alegre-1.394109> Acesso em: jul. 2020

NOGUEIRA, Thiago; LOMBARDI, Renato. PM prende família acusada de comandar tráfico em bairro de Contagem. OTEMPO, Belo Horizonte, 11 jul. 2009. Cidades. Disponível em: <https://www.otempo.com.br/cidades/pm-prende-familia-acusada-de-comandar-trafico-embairro-de-contagem-1.544216> Acesso em: jul. 2020

NUNES, Anna Flávia. Adolescente suspeita de tráfico é apreendida com cocaína e produtos para refino da droga em Betim. OTEMPO, Belo Horizonte, 22 jan. 2010. Cidades.

Disponível em: <https://www.otempo.com.br/cidades/adolescente-suspeita-de-trafico-eapreendida-com-cocaina-e-produtos-para-refino-da-droga-em-betim-1.464421> Acesso em: jul. 2020

PENNA, Fernanda. Adolescente de 15 anos é suspeita de comandar o tráfico em aglomerado da capital. O TEMPO, Belo Horizonte, 22 jan. 2010. Cidades. Disponível em: <https://www.otempo.com.br/cidades/adolescente-de-15-anos-e-suspeita-de-comandar-o-

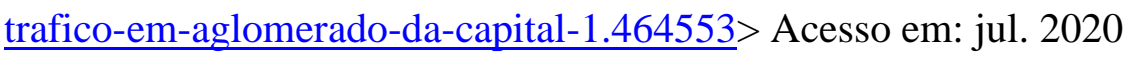

PENNA, Fernanda. Casal é preso com $3 \mathrm{Kg}$ de crack no bairro Nova Cintra. O TEMPO, Belo Horizonte, 03 set. 2009. Cidades. Disponível em: < https://www.otempo.com.br/cidades/casal-e-preso-com-3-kg-de-crack-no-bairro-nova-cintra$\underline{1.534253}>$ Acesso em: jul. 2020

PENNA, Fernanda. Mãe e filho são presos com mais de 800 pedras de crack em Uberlândia. O TEMPO, Belo Horizonte, 25 mai. 2009. Disponível em: < 
https://www.otempo.com.br/cidades/mae-e-filho-sao-presos-com-mais-de-800-pedras-decrack-em-uberlandia-1.495147> Acesso em: jul. 2020.

PENNA, Fernanda. Onze pessoas são presas operação no Morro do Papagaio. O TEMPO, Belo Horizonte, 29 mai. 2009. Cidades. Disponível em: < https://www.otempo.com.br/cidades/onze-pessoas-sao-presas-operacao-no-morro-dopapagaio-1.494764 > Acesso em: jul. 2020

RABELO, Mateus. Cinco pessoas são presas suspeitas de tráfico de drogas no bairro Minas Caixa. O TEMPO, Belo Horizonte, 09 set. 2010. Cidades. Disponível em: < https://www.otempo.com.br/cidades/cinco-pessoas-sao-presas-suspeitas-de-trafico-de-drogasno-bairro-minas-caixa-1.479818> Acesso em: jul. 2020

RAMOS, Raphael. Polícia apreende R\$ 100 mil em crack. O TEMPO, Belo Horizonte, 26 mai. 2006. Cidades. Disponível por: <https://www.otempo.com.br/cidades/policia-apreende-r100-mil-em-crack-1.329202> Acesso em: jul. 2020

RAMOS, Raphael. Polícia encontra crack em máquina de lavar. Super Notícia, Belo Horizonte, 18 ago. 2009. Cidades. Disponível em: $<$ https://www.otempo.com.br/cmlink/2.628/pol\%C3\%ADcia-encontra-crack-emm\%C3\%A1quina-de-lavar-1.62794> Acesso em: jul. 2020

SILVEIRA, Daniel. Quadrilha especializada no tráfico de crack é desarticulada em Poços de Caldas. O TEMPO, Belo Horizonte, 15 mai. 2009. Cidades. Disponível em: <https://www.otempo.com.br/cidades/quadrilha-especializada-no-trafico-de-crack-edesarticulada-em-pocos-de-caldas-1.495834> Acesso em: jul. 2020

SOARES, Mábila. Adolescente é apreendido e mulher é presa com $11 \mathrm{Kg}$ de crack no bairro Novo Tupi. O TEMPO, Belo Horizonte, 17 out. 2011. Cidades. Disponível em: <https://www.otempo.com.br/cidades/adolescente-e-apreendido-e-mulher-e-presa-com-11-kgde-crack-no-bairro-novo-tupi-1.442155> Acesso em: jul. 2020 
SOARES, Mábila. Mulher é presa em casa com $50 \mathrm{Kg}$ de maconha e $2 \mathrm{Kg}$ de crack no bairro Biquinhas. O TEMPO, Belo Horizonte, 17 set. 2012. Cidades. Disponível em:

<https://www.otempo.com.br/cidades/mulher-e-presa-em-casa-com-50-kg-de-maconha-e-2kg-de-crack-no-bairro-biquinhas-1.411989> Acesso em: jul. 2020

SUSPEITO de liderar tráfico em Igarapé é preso pela PM. Estado de Minas, Belo Horizonte, 05 out. 2012. Cidades. Disponível em: < https://www.em.com.br/app/noticia/gerais/2012/10/05/interna_gerais,321549/suspeito-deliderar-trafico-em-igarape-e-preso-pela-pm.shtml> Acesso em: jul. 2020

VEIGA, Igor. Mulher presa com crack diz que iria pagar a dívida a traficantes. O TEMPO, Belo Horizonte, 28 nov. 2007. Disponível em: < https://www.otempo.com.br/cidades/mulherpresa-com-crack-diz-que-iria-pagar-divida-a-traficantes-1.302823> Acesso em: jul. 2020. 